IRA-International Journal of Technology \& Engineering

ISSN 2455-4480; Vol.03, Issue 03 (2016)

Institute of Research Advances

http://research-advances.org/index.php/IRAJTE

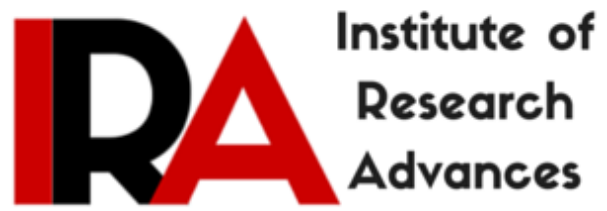

\title{
Essence of Quality Control in Small Manufacturing Industry
}

\author{
Mr. Arijit Mukherjee ${ }^{1}$, Dr. Abhijit Chakraborty ${ }^{2}$, Mr.Sujit Kumar Garai ${ }^{3}$ \\ ${ }^{1}$ Lecturer, Technique Polytechnic Institute, \\ Dist-Hoogly, West Bengal, India. \\ ${ }^{2}$ Principal, Technique Polytechnic Institute, \\ Dist-Hoogly, West Bengal, India. \\ ${ }^{3}$ Lecturer, Technique Polytechnic Institute, \\ Dist-Hoogly, West Bengal, India.
}

DOI: http://dx.doi.org/10.21013/jte.v3.n3.p12

\section{How to cite this paper:}

Mukherjee, A., Chakraborty, A., \& Garai, S. (2016). Essence of Quality Control in Small Manufacturing Industry. IRA-International Journal of Technology \& Engineering (ISSN 2455-4480), 3(3). doi:http://dx.doi.org/10.21013/jte.v3.n3.p12

(C) Institute of Research Advances

\section{(cc) EY-NC}

This works is licensed under a Creative Commons Attribution-Non Commercial 4.0 International License subject to proper citation to the publication source of the work.

Disclaimer: The scholarly papers as reviewed and published by the Institute of Research Advances (IRA) are the views and opinions of their respective authors and are not the views or opinions of the IRA. The IRA disclaims of any harm or loss caused due to the published content to any party. 


ABSTRACT
The SMEs are an important part for world economy. The various categories of SMEs
are spread throughout the world. In some cases they are competing with the big
companies and at some instances they are working as vendor for supplying their
spare parts and ancillaries. But there is a severe problem regarding quality of the
product produced by them. In this paper an attempt has been made to improve the
quality of the product by the help of Quality Control. For this, a particular SME firm
has been studied and analyzed in order to give a solution of the quality related
problems.

Keywords: Quality, continual, improvement, control

\section{Introduction:}

Globalization and Liberalization are the order of the day. The term "quality" has a relative meaning. This is expressed by the ISO definition: "The totality of features and characteristics of a product or service that bear on its ability to satisfy stated or implied needs". In simpler words, one can say that a product has good quality when it "complies with the requirements specified by the client". When projected on analytical work, quality can be defined as "delivery of reliable information within an agreed span of time under agreed conditions, at agreed costs, and with necessary aftercare". The "agreed conditions" should include a specification as to the precision and accuracy of the data which is directly related to "fitness of use" and which may differ for different applications.

The market demand will determine the systems and manner of production. The allocation of resources within the sector must be governed by the criteria of efficiency, competitiveness and productivity. The Small-Scale Industries (SSI) has a crucial role in a developing economy like India. They play a strategic role in the progress of the country through employment generation, resource mobilisation and utilisation, income generation and in helping to promote change in a gradual and phased manner. These industries by and large represent a stage in economic transition from traditional segments to modern segments. The traditional nature of this process is reflected in the diversities of these industries. These enterprises have vast potentialities but they could not progress satisfactorily. Their performance is not good as they face the problems of labour, availability of raw material, absence of credit facility, lack of machinery, etc. Suitable measures are necessary to remove these bottlenecks in the optimum operation of SSI.

Quality control (QC) is a procedure or set of procedures intended to ensure that a manufactured product or performed service adheres to a defined set of quality criteria or meets the requirements of the client or customer. It is an aggregate of activities (as design analysis and inspection for defects) designed to ensure adequate quality especially in manufactured products.

It consists of a set of methods used by organizations to achieve quality parameters or quality goals and continually improve the organization's ability to ensure that a product will meet quality goals.

Quality control is a process through which an enterprise seeks to ensure that product quality is maintained or improved and manufacturing errors are reduced or eliminated. Quality control requires the company to create an environment in which both management and employees strive for perfection. This is done by training 
personnel, creating benchmarks for product quality, and testing products to check for statistically significant variations.

Quality control involves testing of units and determining if they are within the specifications for the final product. The purpose of the testing is to determine any needs for corrective actions in the manufacturing process. Good quality control helps companies meet consumer demands for better products.

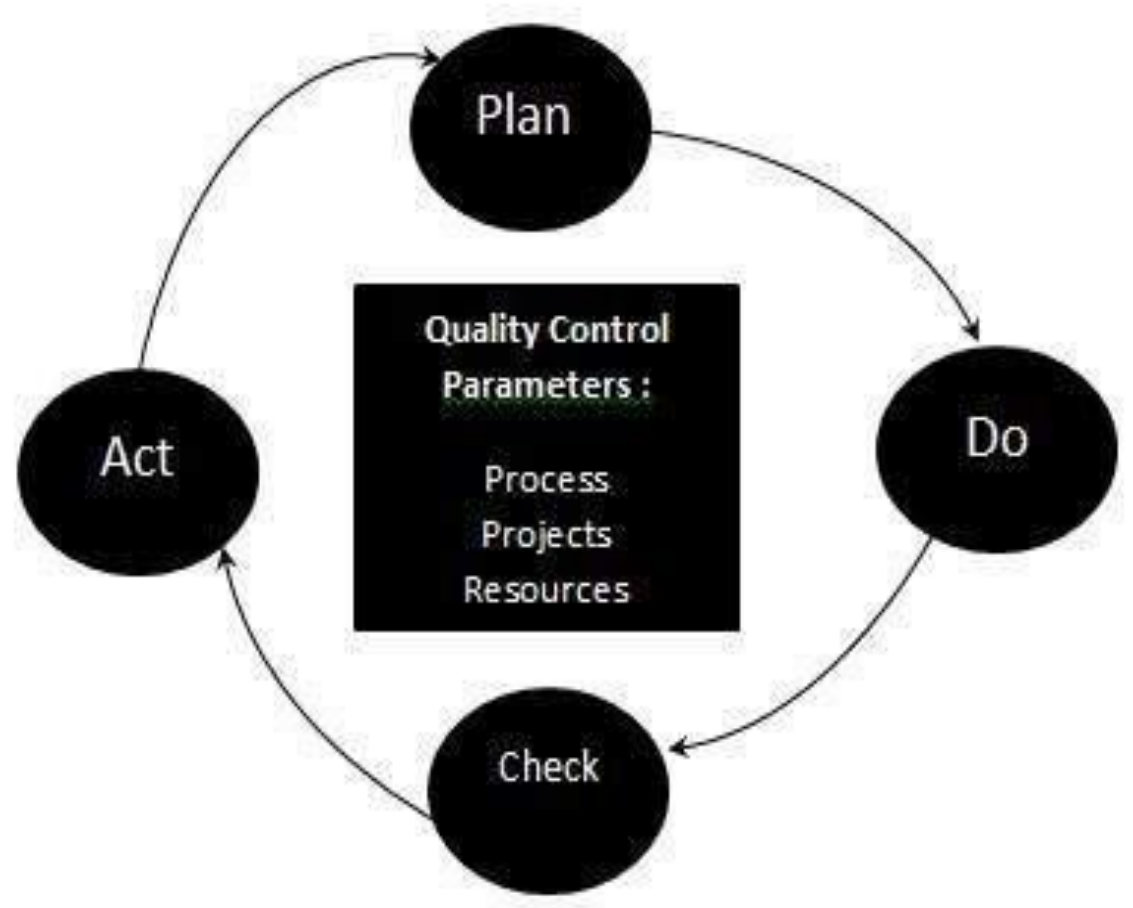

Fig. 1

The total quality control process consists of:

- Plan - It is the stage where the Quality control processes are planned

- Do - Use a defined parameter to develop the quality

- Check - Stage to verify if the quality of the parameters are met

- Act - Take corrective action if needed and repeat the work

\section{Literature Review:}

The small scale unit cannot invest a huge amount in business. This makes them less capital intensive and reduces the entry barrier on account of investment capability. Due to the large population, they offer more employment and mostly use local skills (Vasudevan, 1998). Nations are most engaged in quality management from perspectives of ISO recognizing quality management as tool for improving processes and rising competitiveness of the firm (Janis Preide, 2012). Organization should be directed to customer satisfaction, continuous improvement of their services, company compliance requirements etc (Boca Gratiela Dana 2012).SMEs differ from large firms in many respects including management style, production processes, capital availability, purchasing practices, inventory systems, and negotiating power (Ahire and Golhar, 1996). Ghobadian and Gallear (1996) considered SMEs as the "life blood of modern economies". The success of large organisations in producing or improving 
the quality of products or services depends on the quality of products or components the supplier firms provide to them. Generally, the component suppliers are small and medium-sized firms. Therefore, SMEs face considerable pressure to gain ISO 9000 quality certification particularly if their customers are the government agencies (van der Wiele and Brown, 1998). SMEs face competition from large industries due to lack of funds, lack of infrastructure, challenges on manufactured goods standardization, anti dumping policy, total quality management, poor management etc (Rajib Lahiri, 30).

However, compared with large organisations, SMEs have been slow to adopt the quality management tool such as TQM (Ghobadian and Gallear, 2000). Increasing the efficiency of the SMEs and reducing the spending to enhance productivity and to remain competitive in the market is the key aim which TQM helps to achieve (Dr. Sukhwinder Singh Jolly, 2013). It has also been described as a system that helps organisation to achieve its excellence (Yusof and Aspinwall, 2001).

Hence this study has been conducted with a particular focus on quality control aspects in SME

\section{Case Study:}

A small household light fittings manufacturing industry located at Hooghly district, West Bengal, India has been considered in this case. They are facing a major problem of rejection due to lack of awareness about the quality as well as having improper utilisation of their resources. So number of units is rejection getting higher now a day. Cost per piece is increasing comparing to the market price of other brand. Finally they cannot satisfy the market demand due to inadequate branding.

\section{Methodology:}

The concerned industry has been analyzed across the hierarchy and by having an interaction across the levels. The questionnaire has been provided to the employee and staff members to collect the requisite data and information regarding the research area.

\section{Analysis:}

The staff members of the SME are not having proper idea neither know the importance of Quality. The process they follow in production is also not systematically done. This results in the loss of inventory and increase in the production time. The error is also occurring in between different machines during production process.

It was decided to seek the responses to understand the perceptions about various issues and expectations for the implementation of quality control in SME. After the completion of the questioning part, different analysis has been carried out.

Quality control is primarily aimed at the prevention of errors. Yet, despite all efforts, it remains inevitable that errors are be made. Therefore, the control system should have checks to detect them. The techniques and activities involved in Quality Control can be divided into four levels of operation:

\section{First-line control: Instrument performance check.}

2. Second-line control: Check of calibration or standardization. 
3. Third-line control: Batch control (control sample, identity check).

\section{Fourth-line control: Overall check \\ Proposed Model:}

A Quality Control cycle proposed model as shown in Fig. 2 has been formulated for the SME. It starts with the initiative step where Assessment is to be done and it influences specifications and procedures. Next is the plan. Here the concerned plan is based on assessment of results and standard operating procedures. The plan can only get its success, if properly implemented. The implemented plan is to be monitored against the desired standard and specifications. Then evaluation regarding performance is to be made and accordingly a continuous assessment is to be done. The identified gaps are to be taken care of by the act and if any emergency / urgent situation prevails, necessary measures are to be taken to solve and give a solution for that problem. Again the next step initiation comes. In that way the cycle moves on.

This will make the SME to implement the Quality Control procedure in a better way and result in the reduction of errors and other mistakes that were occurring earlier.

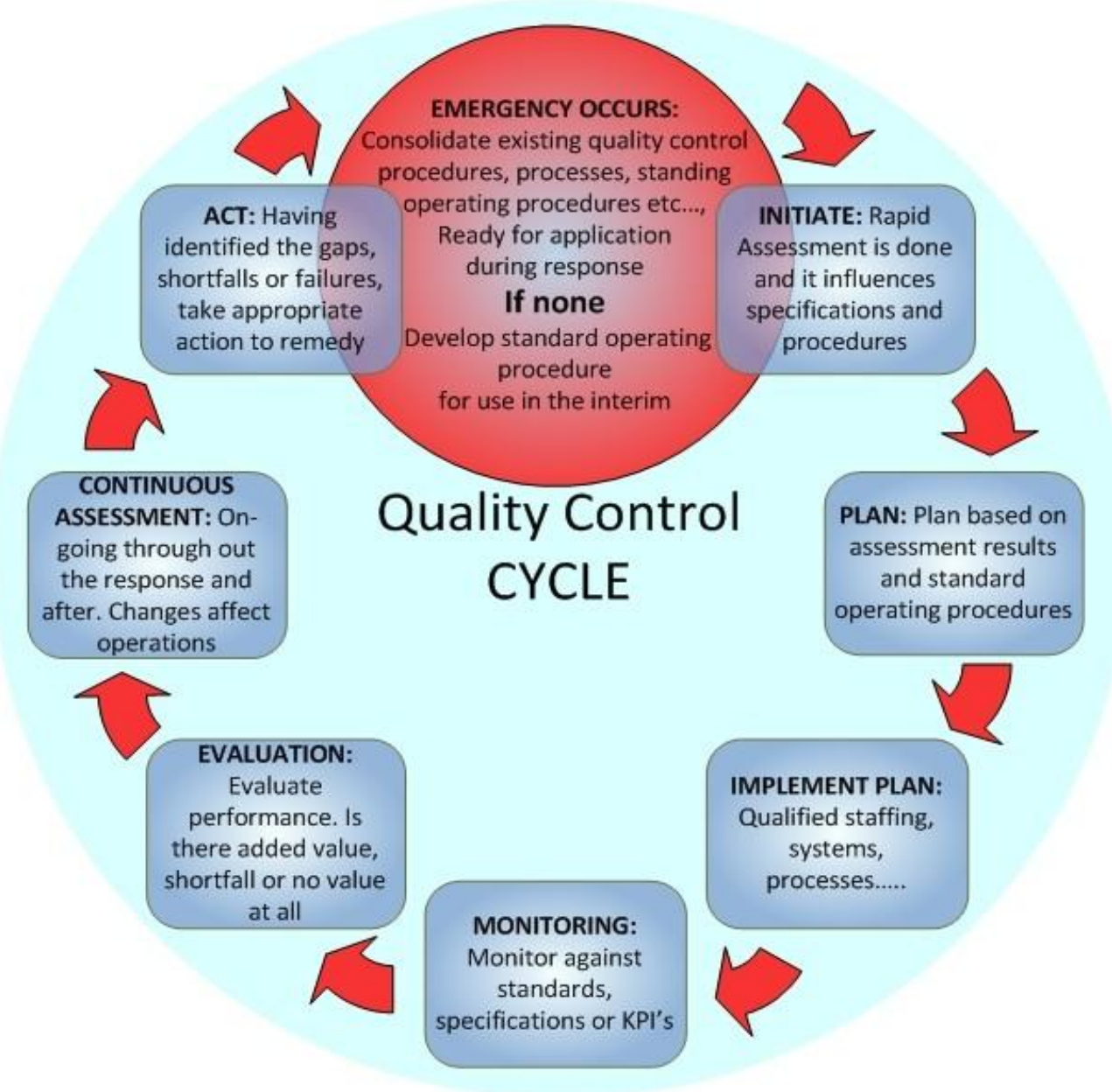

Fig. 2 Quality Control Cycle 


\section{Conclusion:}

The SMEs are developing day by day. But still lots of areas are to be looked into. Quality control is an important area in that aspect. A major aspect of quality control is the establishment of well-defined controls. These controls help standardize both production and reactions to quality issues. Limiting room for error by specifying which production activities are to be completed by which personnel reduces the chance that employees will be involved in tasks for which they do not have adequate training. Now Quality staff also involved in Investigation of consumer complaints, evaluation of new vendors/materials, internal audits to verify compliance to regulations and maintaining relationships with vendors.

Most manufacturing plants produce hundreds or thousands of products daily. Due to volume, QC cannot inspect every product made. This is where scientific sampling comes into play. It is important to have trained individuals in each step of the process. Producing quality products is a team effort requiring the support of the line operators, cleaning and changeover crews and Manufacturing Management.

\section{References:}

[1] Ahire, S.L., \& Golhar, D.Y. (2001).Quality management in large versus small firms. Journal of Small Business Management, 27, 1-13.

[2] 'Big change in small scale', Business India, January 2-15, 1995.

[3] Dana, B. G.,"SWOT analysis to improve quality management production", Procedia - Social and Behavioral Sciences 62,pp. 319 - 324, 2012.

[4] Dr. M.C. Garg “ Entrepreneurship and Small Business Development”

[5] Gallear, D. and Ghobadian, A. (2000), An examination and non-prescriptive model of the TQM

implementation process. Available

[6] Jolly, S. S.,"TQM: An Emerging Necessity for Small Scale Industry Sector", Vol.

2, Issue 1, pp. 36-37, 2013.

[8] Lahiri, R.,"Problems And Prospects of Micro, Small And Medium Enterprises (Msmes) in India in the Era of Globalization".

[9] Narasimhan, G., "Strategic Handling to changes in Small Manufacturing Organizations in India", International Journal of business and Management, Vol.4, No.1, pp.141-148, 2009.

[10] Phan, A.C., Abdallah, A. B., Matsui, Y.,"Quality management practices and competitive performance:Empirical evidencefrom Japanese manufacturing companies", Int. J. Production

Economics 133, pp. 518-529.

[11] Priede, J.,"Implementation of Quality Management System ISO 9001 in the World and its Strategic Necessity", Procedia - Social and Behavioral Sciences 58, pp. $1466-1475,2012$.

[12] Syamsul Bahri (2012) "Implementation of TQM and Its Effect on organization performance of manufacturing Industries", IOSR journal of Business and Management, Vol. 5, Issue 1

[13] Vasudevan, A., " Perspective of the Role of Small Scale Industries in India's Economic Development”, Reserve Bank of India Bulletin, Vol. 3, No. 10, pp.828, 1998.

[14] Yusof, S. M. and Aspinwall, E. (2000a), A conceptual framework for TQM implementation for SMEs, The TQM Magazine, Vol. 12 No. 1, pp. 31-36. 